\title{
Eddy Current Test for Detection of Foreign Material using Rotating Probe
}

Houng Kun ANN, Il Song and Jae-Sul LEE

OReum Inc.

\begin{abstract}
There are several elements that affect on the integrity of steam generator tubes. One of the elements is loose parts located on outside of the tubes. It causes erosion which is possible to lead fatal defect like crack on the outside surface of the tubes. In this study, artificial loose parts on Inconel 690 tube are demonstrated and eddy current testing data of the region is acquired using rotating probe. Ferromagnetic and nonmagnetic foreign materials were used to demonstrate artificial loose parts. Eddy current channel of $100 \mathrm{KHz}$ frequency shows definite signals of those foreign materials but stainless steel was not clearly detected. This result can be explained based on the electrical conductivity of the materials and it can be confirmed with lissajous window and C-scan. In addition, no indication was detected when the distance of the gap between the foreign materials and the tube is increased to more than $3 \mathrm{~mm}$ under this test condition. Based on these experimental inspections, we were able to find suitable methods for analyzing the signals obtained under various conditions that could occur when conducting steam generator eddy current test in NPP.
\end{abstract}

Key words: ECT (eddy current test), heat exchanger tube, foreign material, rotating probe.

\section{Introduction}

ECT (eddy current test) using Rotating probe is mostly utilized technique in nuclear power plant for steam generator tube. And the signal from materials is in variety based on the materials.

Foreign material in steam generator could be severely harmful on the integrity of tubes and therefore its early detection to remove is very important.

But it is not easy to distinguish the signal of real foreign materials from non-relevant signals. So it is needed for providing various and specific signal data from di-verse materials by practical demonstration as references.

This paper presents eddy current techniques that are used in plants, and indications acquired from demonstration of possible foreign material on tubes and difference between the materials mostly used in the industry.

Corresponding author: Houng Kun Ann, M.Sc, research fields: ECT, UT, and PAUT.

\section{Theory}

\subsection{Steam Generator in Nuclear Power Plant}

Steam generators are heat exchangers used to convert water into steam to supply steam into the turbine to generate electricity. They consist of primary and secondary coolant loops. The function of the steam generator is to transfer the heat from the reactor cooling system to the secondary side of the tube.

The water supplied to the steam generators must be very pure, free of particles. And these particles can cause unpredictable failure in ensuring integrity of tubes. The fluid of primary loop is highly contaminated. So it is very important to prevent mixing of the two fluids in the two loops.

In Korea, steam generators are mostly installed vertically and tubes are u-bend type. Steam generators consist of major parts including moisture separator, tube supports, chamber, divide plate, outlet and inlet nozzles and etc. Tubes are firmly installed in tube-sheet by hydraulic expansion or explosive expansion, and most foreign materials were found right above tube-sheet. Fig. 1 shows the structure of a typical steam 
generator in Korea.

\subsection{Eddy Current Test and Preparations}

Tubes installed in a steam generator are around 5,000-8,000. So ECT is the most effective NDT (non-destructive testing) method providing surface/near surface condition of the tubes in a limited time and also in radiation environment of nuclear power plant.

Equipment and test tubes used for demonstration of detecting foreign materials are equivalent to equipment and tubes being used at actual field. The operating frequencies are also selected according to procedure used at field. Pan cake coil and Plus point coil are used at a same time for data acquisition and ASME calibration standard is used for signal calibration.

MIZ-70 and MIZ-80iD manufactured in ZETEC are used for data acquisition. For probe traveling, PM-3A, 10D Power Supply and 10D Push-puller are used. For data analysis, Eddynet software on HP-UX system is used. Fig. 2 is the picture of those equipment setup for data acquisition.

Materials for the demonstration are selected considering the possibility of foreign material inclusion as below.

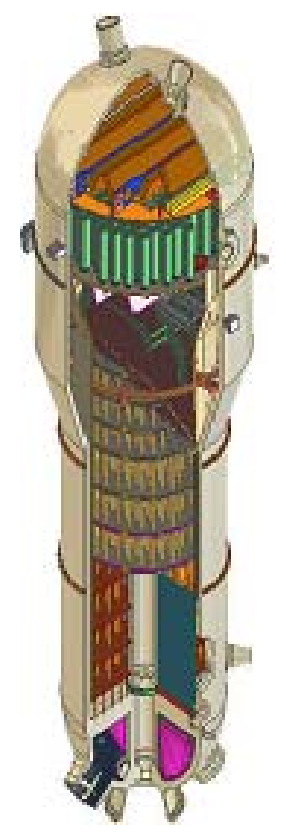

Fig. 1 General steam generator.

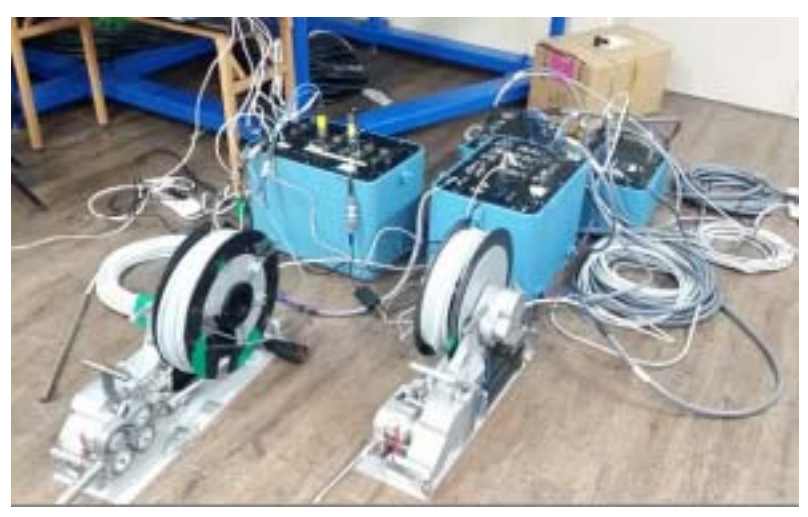

Fig. 2 Equipment for demonstration.

(1) Sludge

(2) Aluminum

(3) SS400 (ferromagnetic)

(4) Carbon Steel (ferromagnetic)

(5) Stainless Steel

(6) Copper

(7) Slag

According to IACS table, Aluminum has conductivity around 62.7 IACS\%. SS400 has 17.6 IACS\%, Stainless Steel 2.4 IACS\%, Copper 24.6 34.5 IACS\% and slag is non-conductive material. It is thought that SS400 and carbon steel show strong response due to their magnetic characterization.

The operating frequencies were determined according to practical procedure used at fields considering the tube material and thickness. They are 400, 300, 100, $20 \mathrm{kHz}$. Multiple frequency inspections are commonly used for tubing inspections. There are tube support plates in steam generator. Foreign materials are usually located on the plate. Due to the big signal from the plate, foreign material signals are hidden in the big signal of the plate. Suppression process is normally used to get rid of unnecessary signal from tube support plates. It is a process of subtracting and mixing the result of a lower frequency signal with high frequency signal. It allows the assessment of small defects in this area.

In this test, it is considered that 400 and $300 \mathrm{kHz}$ are not important due to the theory of depth penetration. In high frequency, it is almost impossible to detect any foreign material on outside surface of 
tube. The standard depth penetration of 400 and 300 $\mathrm{kHz}$ is less than the thickness of the test tube. It is thought that only frequencies of 100 and $20 \mathrm{kHz}$ present detectable signal from foreign materials. The equation for standard depth penetration is addressed below.

$$
\begin{aligned}
& \delta=\frac{1}{\sqrt{\pi f \mu \sigma}} \\
& \delta=\text { Standard Depth of Penetration (mm) } \\
& \mathrm{f}=\text { Test Frequency (Hz) } \\
& \mu=\text { Magnetic Permeability (H/mm) } \\
& \sigma=\text { Electrical Conductivity (\% IACS) }
\end{aligned}
$$

Data acquisition is performed in two ways. First test (Fig. 3) was a case that foreign materials are located between the two tubes contacting outside surface of the both tubes. Second test (Fig. 4) was the other case that the foreign materials are located contacting at one tube with gap between tube and foreign materials. The gap was increased from 0 to 5 $\mathrm{mm}$ with $1 \mathrm{~mm}$ step. Data were acquired with MIZ-70 and MIZ-80iD to compare data quality. Recording speed was set as $0.5 \mathrm{inch} / \mathrm{sec}$ to get more than 25,30 samples/inches for axial and circumferential direction, respectively.

\section{Results}

\subsection{First Test}

Foreign materials were detected in $100 \mathrm{kHz}$ and 20 $\mathrm{kHz}$ frequency channels. 400 and $300 \mathrm{kHz}$ were also reviewed but there is no detectable signal response from foreign material. The C-scan and lissajous signal acquired from a tube with foreign material demonstrated is shown in Fig. 5.

Aluminum, copper, stainless steel were non-ferromagnetic materials used for this test. Aluminum and copper have higher conductivity than stainless steel. For aluminum and copper, $100 \mathrm{kHz}$ channel shows clear indication signal but it was hard to recognize indications in $20 \mathrm{kHz}$ channel. It shows that mid-frequency channel is better for detection of non-ferromagnetic materials than low-frequency

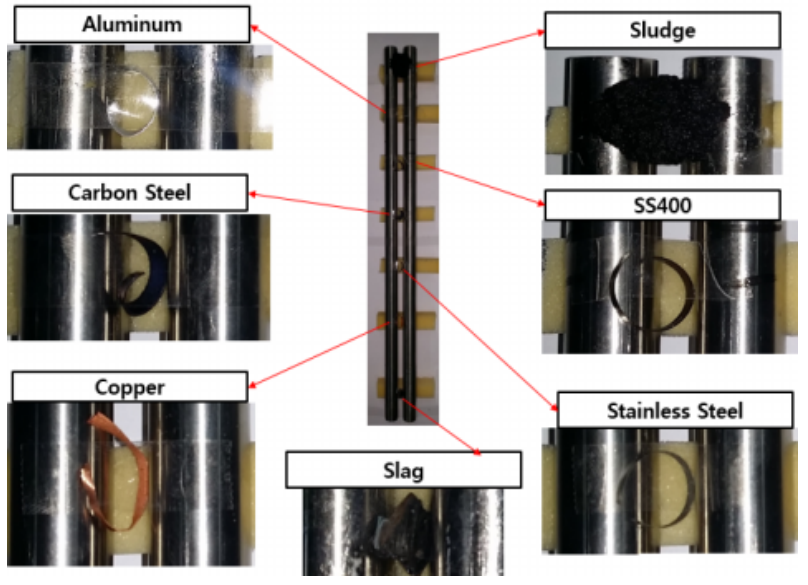

Fig. 3 First test.

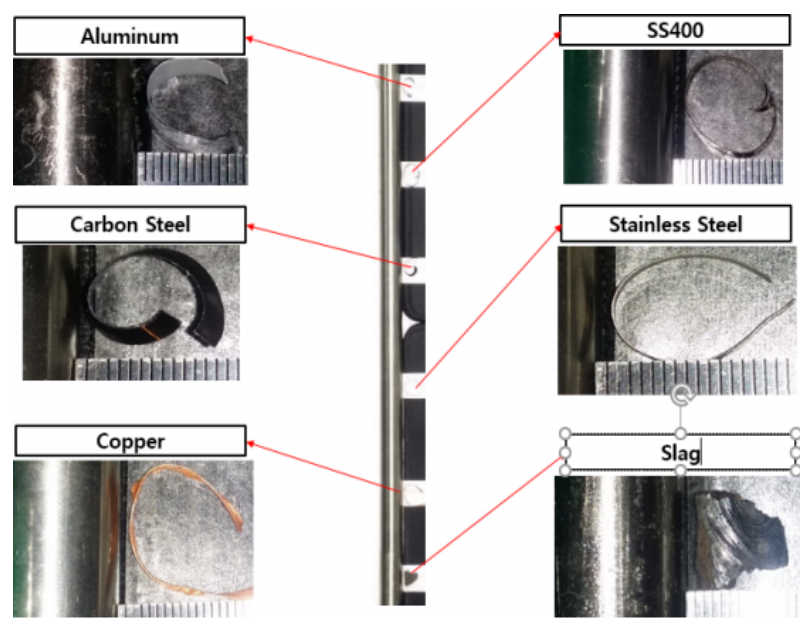

Fig. 4 Second test.

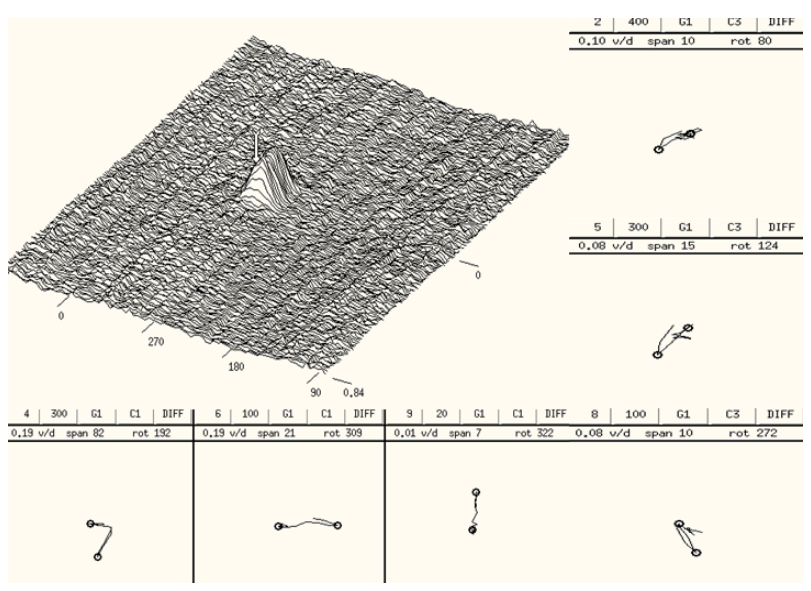

Fig. 5 ECT signal of a test tube.

channel. For stainless steel, it was hard to detect any indication signal. It is considered because stainless steel has too low conductivity. But only when contacting area of stainless steel is large enough, the indication signal was detectable. 
SS400 and Carbon Steel are ferromagnetic materials used for this test. It was quite easy to detect the indication of foreign material in both $100 \mathrm{kHz}$ and 20 $\mathrm{kHz}$ channel.

Indication signals from each material in lissajous window and C-scan are shown as below. Fig. 6 through 9 show differential signals of eddy current at 100 and $20 \mathrm{kHz}$ from each foreign material. Positive C-scan signals from SS400 and carbon steel are shown in Figs. 6 and 7, respectively. They are ferromagnetic materials. On the other hand, signals from aluminum and copper which are non-ferromagnetic materials show negative direction of C-scan image in Figs. 8 and 9.

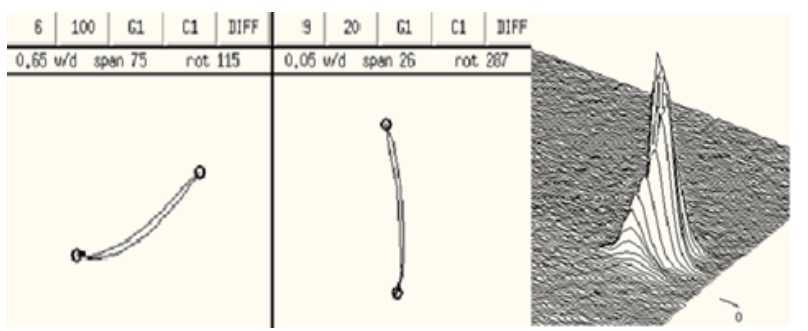

Fig. 6 SS400 signal.

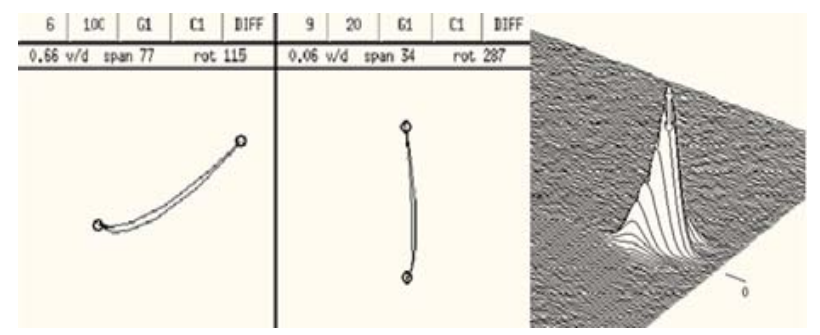

Fig. 7 Carbon steel signal.

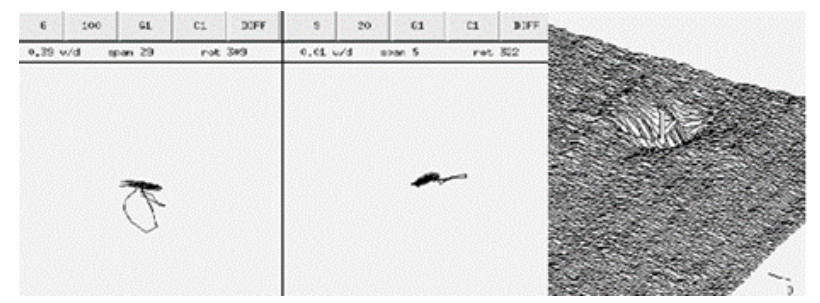

Fig. 8 Aluminum signal.

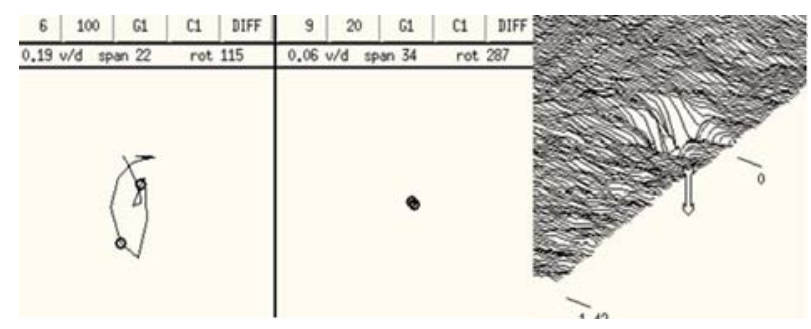

Fig. 9 Copper signal.

\subsection{Second Test}

Second test is performed adjusting the gap between tube surface and foreign material from 0 to 5 mm with $1 \mathrm{~mm}$ increment. $20 \mathrm{kHz}$ and $100 \mathrm{kHz}$ channels are reviewed as detection frequency channel. With the gap of $1 \mathrm{~mm}$, only ferromagnetic materials (Carbon Steel and SS400) are detected in both channels. But it is practically hard to recognize the indication from background noise in $100 \mathrm{kHz}$ channel. With the gap of $2 \mathrm{~mm}$, detectable response is shown in $20 \mathrm{kHz}$ channel. Demonstration with more than $3 \mathrm{~mm}$ gap, indications of the foreign material were not detectable.

Figs. 10-12 show C-scan signal image when the gaps between material and tube are 0,1 and $2 \mathrm{~mm}$ respectively for SS400 and carbon steel.

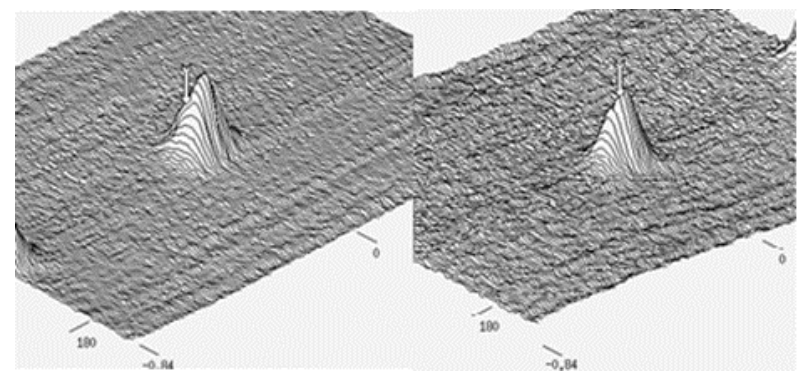

Fig. $100 \mathrm{~mm}$ spacing (left is $\mathrm{SS} 400$ and right is carbon steel).

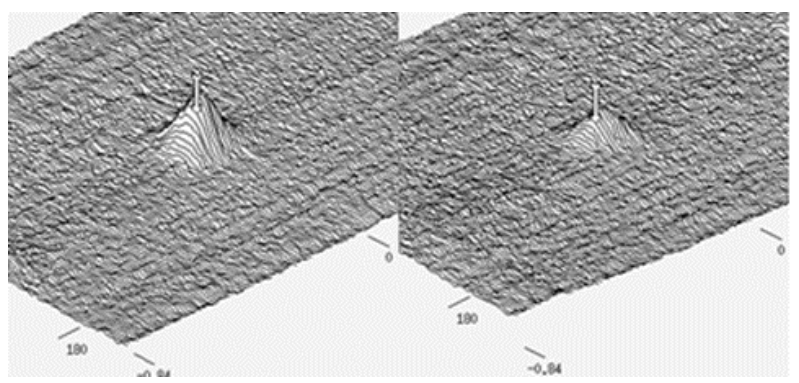

Fig. $111 \mathrm{~mm}$ spacing (left is SS400 and right is carbon steel).

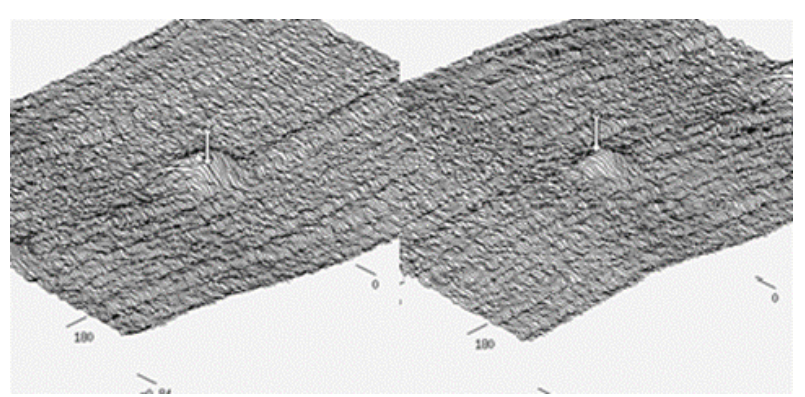

Fig. $122 \mathrm{~mm}$ spacing (left is SS400 and right is carbon steel). 


\section{Conclusions}

Detection test of foreign material on steam generator tube was performed using eddy current rotating probe.

Data were acquired with two different instruments, MIZ-70 and MIZ-80iD, to compare signal quality between them. There was no significant difference in signal quality but MIZ-80iD shows better signal to noise ratio, so it was easier to recognize the indications in strip chart and C-scan.

For ferromagnetic foreign materials even with small contacting area, both 20 and $100 \mathrm{kHz}$ channel show clear signal response. $20 \mathrm{kHz}$ channel shows stronger indication signal than $100 \mathrm{kHz}$ channel.

For non-ferromagnetic foreign materials like aluminum and copper which has higher conductivity than stainless steel, indication was shown in $100 \mathrm{kHz}$ channel more clearly than in $20 \mathrm{kHz}$ channel. For stainless steel, it is not clearly detected in both channels. It is because that stainless steel has lower conductivity than other non-ferromagnetic materials.

There was no detectable signal when the gap between tube and foreign material is more than $3 \mathrm{~mm}$. When small gap was simulated, indication was detected in $20 \mathrm{kHz}$ channel.
For clarification and verification of the foreign materials from eddy-current signals, Foreign Object Search and Retrieval Remote Visual Technique are necessary.

\section{References}

[1] Clerk Maxwell, J., ed. 1892. A Treatise on Electricity and Magnetism. 3rd ed. vol. 2. Oxford: Clarendon, 53-75.

[2] Bose, M. S. C. 1986. "A Study of Fatigue in Ferromagnetic Materials Using Magnetic Hysteresis Technique.” NDT International 19 (2): 83-7.

[3] Chuang, S. F. 1997. "Eddy Current Automatic Flaw Detection System for Heat Exchanger Tubes in Steam Generators.” Iowa State University, 1-20.

[4] Placko, D., and Dufour, I. 1992. "Eddy Current Sensors for Nondestructive Inspection of Graphite Composite Materials.” In Proceedings of the IEEE Conference of the Industry Applications Society (IAS'92), 1676-82.

[5] Ramos, H., Postolache, O., and Alegria, F. C. 2009. "Using the Skin Effect to Estimate Cracks Depths in Metalic Structures." Proceedings of the IEEE Instrumentation and Measurement Technology Conference (I2MTC 2009). Singapore.

[6] Park, D. G., et al. 2008. "Development of New Probe Separating the Permeability Variation Signal in the SG Tube.” J. Korean Soc. Nondestruct. Test. 12: 9-15.

[7] Hussey, D., and Millett, P. 2004. "Fundamental Assessment of Steam Generator Line Contact Tube Support Fouling.” Electric Power Research Institute, 2-21. 